\title{
SELF-MICROEMULSIFYING DRUG DELIVERY SYSTEM
}

\author{
SONIA ANAND*, RISHIKESH GUPTA, PRAJAPATI SK
}

Department of Pharmacy, Bundelkhend University, Jhansi, Uttar Pradesh, India. Email: soniaanand002@gmail.com

Received: 31 May 2016, Revised and Accepted: 20 June 2016

\begin{abstract}
Oral route is the most convenient route of drug administration in many diseases and till today it is the first way investigated in the development of new dosage forms. The major problem in oral drug formulations is low and erratic bioavailability, which mainly results from poor aqueous solubility, thereby pretense problems in their formulation. More than $40 \%$ of potential drug products suffer from poor water solubility. For the therapeutic delivery of lipophilic active moieties (biopharmaceutical classification system Class II drugs), lipid-based formulations are inviting increasing attention. Currently, a number of technologies are available to deal with the poor solubility, dissolution rate, and bioavailability of insoluble drugs. One of the promising techniques is self-microemulsifying drug delivery systems (SMEDDS). SMEDDS have gained exposure for their ability to increase solubility and bioavailability of poorly soluble drugs. SMEDDS, which are isotropic mixtures of oils, surfactants, solvents, and co-solvents/surfactants can be used for the design of formulations to improve the oral absorption of highly lipophilic drug compounds. Conventional SMEDDS are mostly prepared in a liquid form, which can have some disadvantages. SMEDDS can be orally administered in soft or hard gelatin capsules and form fine relatively stable oil-in-water emulsions. Solid-SMEDDS are prepared by solidification of liquid/semisolid self-micron emulsifying ingredients into powders, have gained popularity. This article gives a complete overview of SMEDDS, but special attention has been paid to formulation, design, evaluation, and little emphasis on application of SMEDDS.
\end{abstract}

Keywords: Self-microemulsifying drug delivery system, Surfactant, Oil, Co-surfactant, Bioavailability, Lipophilic, Biopharmaceutical classification system Class II drugs.

(C) 2016 The Authors. Published by Innovare Academic Sciences Pvt Ltd. This is an open access article under the CC BY license (http://creativecommons. org/licenses/by/4. 0/) DOI: http://dx.doi.org/10.22159/ajpcr.2016.v9s2.13180

\section{INTRODUCTION}

Self-microemulsifying drug delivery system (SMEDDS) are defined as isotropic mixtures of natural or synthetic oils, solid or liquid surfactants, or alternatively, one or more hydrophilic solvents, and cosolvents/surfactants that have a unique ability of forming fine oilin-water $(\mathrm{o} / \mathrm{w})$ microemulsions on mild agitation followed by dilution in aqueous media, such as gastrointestinal (GI) fluids. SMEDDS spread readily in the GI tract (GIT), and the digestive motility of the stomach and the intestine provide the agitation necessary for self-emulsification. The basic difference between self-emulsifying drug delivery systems (SEDDS) also called as self-emulsifying oil formulation and SMEDDS is SEDDS typically produce opaque emulsions with a droplet size between 100 and $300 \mathrm{~nm}$ while SMEDDS form transparent microemulsions with a droplet size of $<50 \mathrm{~nm}$ also the concentration of oil in SMEDDS is $<20 \%$ as compared to $40-80 \%$ in SEDDS. Although a number of methodologies can be adapted to improve solubilization of poor water soluble drug and further to improve its bioavailability, SMEDDS are physically stable formulations that are easy to manufacture [1]. Thus, for lipophilic drug compounds that exhibit dissolution rate-limited absorption, these systems may offer an improvement in the rate and extent of absorption and result in more reproducible blood-time profiles (Table 1).

Oral route is the easiest and most convenient way of noninvasive administration. Oral drug delivery systems being the most cost-effective have always lead the worldwide drug delivery market. This oral route may be a problem route for drug molecules which exhibit poor aqueous solubility. When a drug is administered by the oral route, the first step for it to get absorbed is its solubilization followed by permeation. Approximately, $40 \%$ of new chemical entities exhibit poor aqueous solubility and present a major challenge to modern drug delivery system. A rate limiting step for the absorption of these drugs is often their solubilization in the GIT. These drugs are classified as Class II drug by Biopharmaceutical classification system (BCS), drugs with poor aqueous solubility and high permeability. Different formulation approaches such as micronization, solid dispersion, and complexation with cyclodextrins have come up. Indeed, in some selected cases, these approaches have been successful, but they offer many other disadvantages [2].

Being hydrophobic, i.e., more lipophilic a lipid-based drug delivery system would ideally work for a poorly water soluble drug. SMEDDS are usually prepared in a liquid dosage form that can be administered in soft gelatin capsules, which have some disadvantages particularly in the manufacturing process and incompatibility problems with the shells of soft gelatin. Solid-SMEDDS have recently been described and they surmount the disadvantages of liquid SMEDDS as well as exhibited more commercial potential and patient acceptability. Many techniques are offered to convert conventional liquid SMEDDS to solid such as adsorptions to solid carriers, spray drying, spray cooling, melt extrusion, nanoparticles technology, and supercritical fluid-based methods.

Some studies have suggested that the use of SMEDDS could not only increase the GI adsorption but also rectal and vaginal adsorption of poorly water-soluble drugs. Khoo et al. (1998) demonstrated enhanced drug absorption when using long chain triglycerides compared with medium chain triglycerides in the SMEDDS formulations [3]. SMEDDS offer numerous advantages such as spontaneous formation, thermodynamic stability, improved bioavailability, and feasibility for preparation. Enhanced solubility and improved bioavailability are among the main advantage of SMEDDS [4].

\section{Principle}

The basic principle of this system is its ability to form fine oil-inwater microemulsions under gentle agitation following by aqueous phase [5]. SMEDDS can enhance drug absorption through improved dissolution and diffusion, facilitated intestinal lymphatic transport of drugs, protection against enzymatic hydrolysis, and inhibition of efflux by P-glycoprotein. This method has been shown to be effective for BCS II drugs, for example, silymarin, oridonin, and curcumin. Although SMEDDS has been reported to increase the bioavailability of many drugs by increasing water solubility, the increase in bioavailability of BCS IV compounds using SMEDDS is limited [6]. 
Table 1: LFCS showing typical compositions and properties of lipid-based drug delivery system

\begin{tabular}{|c|c|c|}
\hline $\begin{array}{l}\text { Formulation } \\
\text { type }\end{array}$ & Composition & Characteristics \\
\hline Type 1 & $\begin{array}{l}\text { Oils without } \\
\text { surfactants }\end{array}$ & $\begin{array}{l}\text { Non-dispersing, poor solvent } \\
\text { capacity except for highly } \\
\text { lipophilic drugs, requires } \\
\text { digestion to release drug }\end{array}$ \\
\hline Type II & $\begin{array}{l}\text { Oils and } \\
\text { water-insoluble } \\
\text { surfactants }\end{array}$ & $\begin{array}{l}\text { SEDDS, turbid } \\
\text { o/w dispersion (particle size } \\
0.25-2 \mu \mathrm{m} \text { ), unlikely to lose } \\
\text { solvent capacity on dispersion, } \\
\text { possible loss of solvent capacity } \\
\text { on digestion }\end{array}$ \\
\hline Type III & $\begin{array}{l}\text { Oils, } \\
\text { water-soluble } \\
\text { surfactants and } \\
\text { co-solvent }\end{array}$ & $\begin{array}{l}\text { SEDDS/SMEDDS, slightly bluish } \\
\text { to clear dispersion, possible } \\
\text { loss of solvent capacity on } \\
\text { dispersion, less easily digested, } \\
\text { possible loss of solvents solvent } \\
\text { capacity on digestion }\end{array}$ \\
\hline Type IV & $\begin{array}{l}\text { Water-soluble } \\
\text { surfactants and } \\
\text { co-solvent (oil } \\
\text { free) }\end{array}$ & $\begin{array}{l}\text { Forms a clear micellar solution } \\
\text { on dispersion, likely loss of } \\
\text { solvent capacity on dispersion } \\
\text { unlikely to be digested }\end{array}$ \\
\hline
\end{tabular}

SEDDS: Self-emulsifying drug delivery systems, SMEDDS: Self-microemulsifying drug delivery systems, LFCS: Lipid formulation classification system

This delivery system had a few limitations, such as stability, the manufacturing methods, the interaction between the filling and the capsule shell, and the storage temperature. When the product is kept at lower temperatures, there may be some precipitation of the active ingredient and/or the excipients [7].

\section{History of micronemulsions}

The term microemulsion was first used by Hoar and Shulman, Professors of chemistry at Cambridge University, in 1943.

\section{Microemulsions are formed when:}

i. The interfacial tension at the oil/water interface is brought to a very low level and,

ii. The interfacial layer is kept highly flexible and fluid.

These two conditions are usually met by a careful and precise choice of the components and their respective proportions, and by the use of a "co-surfactant" which brings flexibility to the oil/water interface. These conditions lead to a thermodynamically optimized structure, which is stable as opposed to conventional emulsions and does not require high input of energy (through agitation) to be formed. Because the size of the particles is much smaller than the wavelength of visible light, microemulsions are transparent, and their structure cannot be observed through an optical microscope [8].

\section{NEED OF SMEDDS}

Oral delivery of poorly water-soluble compounds is to pre-dissolve the compound in a suitable solvent and fill the formulation into capsules. The main benefit of this approach is that pre-dissolving the compound overcomes the initial rate-limiting step of particulate dissolution in the aqueous environment within the GIT. If the drug can be dissolved in a lipid vehicle, there is less potential for precipitation on dilution in the GIT, as partitioning kinetics will favor the drug remaining in the lipid droplets. Another strategy for poorly soluble drugs is to formulate in a solid solution using a water-soluble polymer to aid solubility of the drug compound. Classification of Biopharmaceutical classification system class of drugs shown in Fig. 1 One potential problem with this type of formulation is that the drug may favor a more thermodynamically stable state, which can result in the compound crystallizing in the polymer matrix [9].

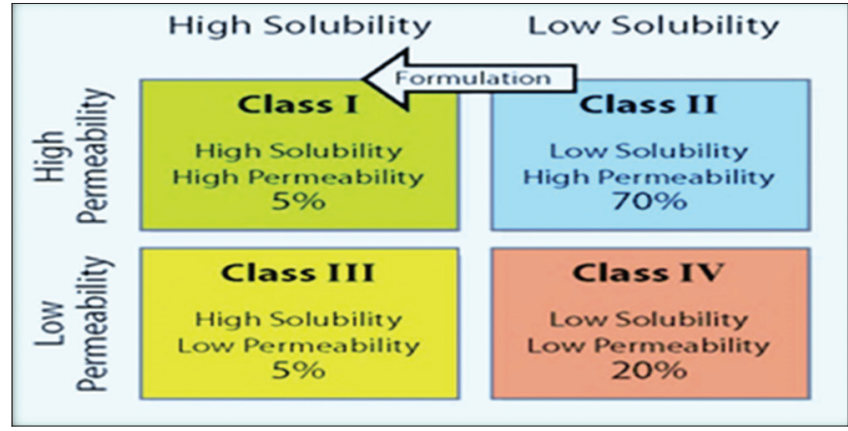

Fig. 1: Classification of biopharmaceutical classification system class of drugs

\section{Advantages of SMEDDS}

- Improvement in oral bioavailability by increasing solubility and efficient drug transport.

- Ease of manufacture and scale-up as compared to other lipid dosage forms.

- Reduction in inter- and intra-subject variability and food effects.

- Ability to deliver peptides that are prone to enzymatic hydrolysis in GIT.

- No influence of lipid digestion process unlike the other lipid-based drug delivery systems.

- When polymer is incorporated in the composition of SMEDDS, it gives prolonged release of medicament [10].

\section{Disadvantages of SMEDDS}

- Lack of good predicative in vitro models for assessment of the formulations.

- This in vitro model needs further development and validation before its strength can be evaluated.

- Further development will be based on in vitro - in vivo correlations and therefore different prototype lipid-based formulations needs to be developed and tested in vivo in a suitable animal model.

- Another is chemical instabilities of drugs and high surfactant concentrations in formulations (approximately 30-60\%) which irritate GIT.

- Moreover, volatile cosolvents in the conventional selfmicroemulsifying formulations are known to migrate into the shells of soft or hard gelatin capsules, resulting in the precipitation of the lipophilic drugs.

- The precipitation tendency of the drug on dilution may be higher due to the dilution effect of the hydrophilic solvent [11].

\section{MECHANISM OF SMEDDS}

The emulsion is stabilized by the surfactant molecules that form a film around the internal phase droplet. In case of SMEDDS, the free energy of formation is very low and positive or even negative which results in thermodynamic spontaneous emulsification.

It has been suggested that self-emulsification occurs due to penetration of water into the liquid crystalline (LC) phase that is formed at the oil/surfactant-water interface into which water can penetrate assisted by gentle agitation during self-emulsification.

After water penetrates to a certain extent, there is disruption of the interface and a droplet formation (Fig. 2). This LC phase is considered to be responsible for the high stability of the resulting microemulsion against coalesce [12].

\section{Formulation components of SMEDDS}

- Active pharmaceutical ingredient

- Oil

- Surfactant

- Co-surfactant 


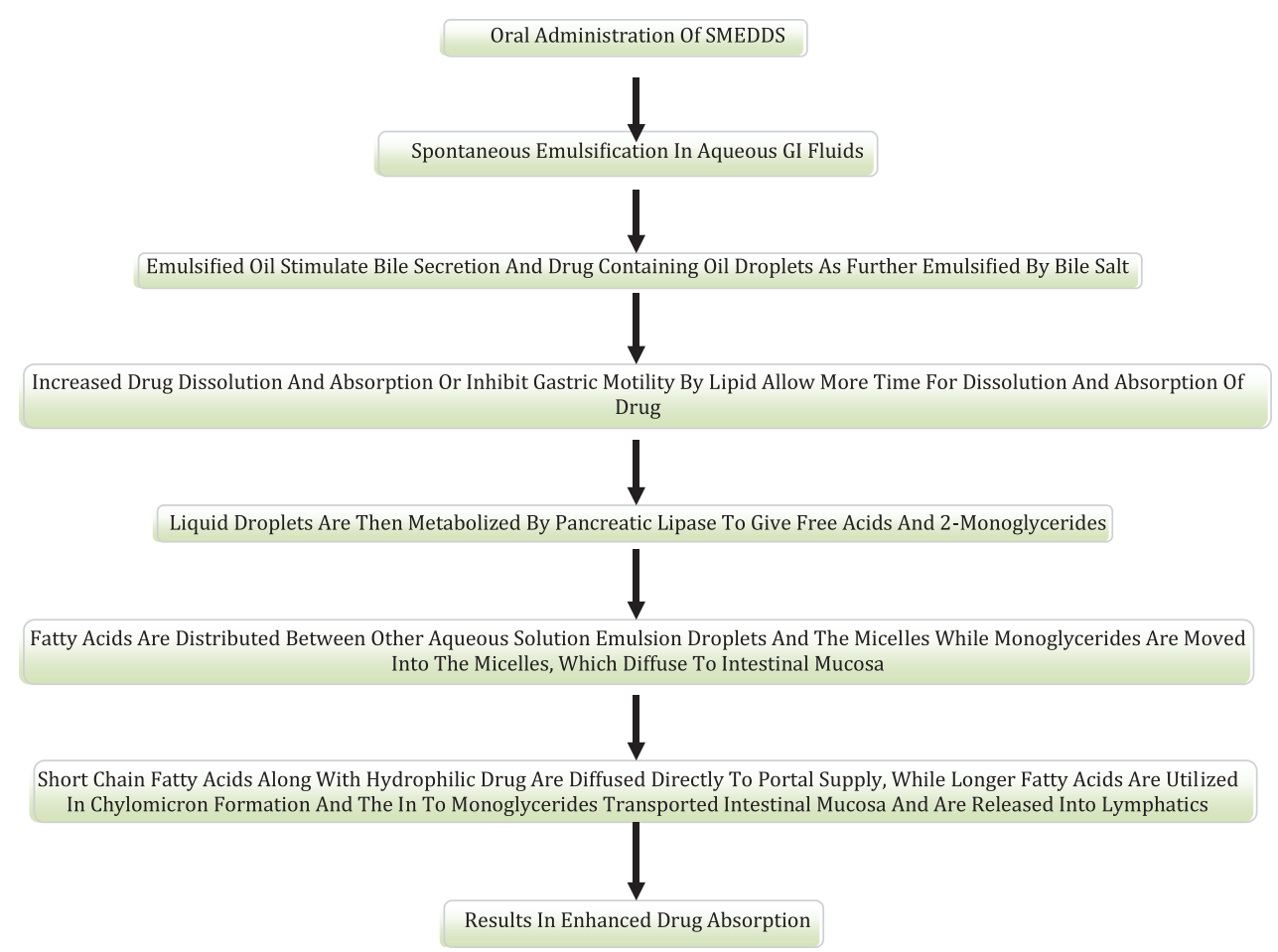

Fig. 2: Mechanisms proposed for bioavailability enhancement of drug

- Co-solvents

- Other components.

- Active pharmaceutical ingredient: Drug should be soluble in oil phase as this influence the ability of SMEDDS to maintain the API in solubilized form. Lipophilic drugs, such as cinnarizine with $\log p>5$, are good candidate for SMEDDS [13]

- Oil: Oil is the most important excipient in the formulation of SMEDDS as it solubilizes the lipophilic drug in required quantity. The main criterion for selecting the oil is that the drug should have high solubility in it, so this will minimize the volume of the formulation for the delivery of effective dose [14].

- Surfactant:

- Anionic surfactants, where the hydrophilic group carries a negative charge. Examples: Potassium laurate, sodium lauryl sulfate.

- Cationic surfactants, where the hydrophilic group carries a positive charge. Example: Quaternary ammonium halide.

- Ampholytic surfactants (Zwitterionic surfactants) contain both a negative and a positive charge. Example: Sulfobetaines.

- Nonionic surfactants, where the hydrophilic group carries no charge but derives its water solubility from highly polar groups. Examples: Sorbitan esters (Spans), polysorbates (Tweens).

- Co-surfactant: For the production of an optimum SMEDDS, high concentration of surfactant is required to reduce interfacial tension sufficiently, which can be harmful, so co-surfactants are used to reduce the concentration of surfactants. In general, cosurfactant of HLB value 10-14 is used such as ethanol, propylene glycol, polyethylene glycol.

- Co-solvents: Organic solvents enable the dissolution of large quantities of either the hydrophilic surfactant or the drug in oil phase. Examples: Ethanol, butanol, propylene glycol, etc., esters such as ethyl propionate, tributyl citrate and amides as 2-pyrolidine, caprolactum, and polyvinyl pyrollidine [15].

- Other components: Other components include pH adjusters, flavors, and antioxidants, consistency builder, enzyme inhibiter, polymers, etc. (Table 2).
Formulation design of SMEDDS

- Screening of Oil: To find out appropriate oil with good solubilizing capacity of API, the saturation solubility of API was investigated in some oils by shake flask method. An excess amount of API was added to vial containing $0.5 \mathrm{~g}$ of each solvent. After sealing, the mixture was vortexed using a cyclomixer for 10 minutes to facilitate proper mixing of API with the vehicles. Mixtures were kept for $72 \mathrm{hrs}$ at ambient temperature to attain equilibrium, and afterward, mixtures were centrifuged at suitable rpm for 15 minutes. Aliquots of supernatant were filtered through membrane filter $(0.45 \mu \mathrm{m})$ and diluted with mobile phase. Drug content was quantified directly by using highperformance liquid chromatography (HPLC) technique.

- Screening of Surfactant: To find appropriate surfactant with good solubilizing capacity, after screening of oil emulsifying ability of different surfactants with the screened oil was investigated. $0.3 \mathrm{~g}$ of surfactant and $0.3 \mathrm{~g}$ of oil phase were weighed and vortexed for 2 minutes followed by warming at $40-45^{\circ} \mathrm{C}$ for 30 seconds, so we can obtain an isotropic mixture. $50 \mathrm{mg}$ of isotropic mixture was taken and diluted with double distilled water previously filtered through $(0.45 \mu \mathrm{m})$ membrane filter in a volumetric flask. A number of volumetric flask inversions was observed visually to form a clear emulsion. The resulting emulsions allowed standing for $2 \mathrm{hrs}$ after that transmittance were observed at $638 \mathrm{~nm}$. The surfactant which forms a clear emulsion with lesser number of inversions and with more transmittance was selected [16].

- Screening of co-surfactant: To find appropriate co-surfactant with good solubilizing capacity, after screening of oil emulsifying ability of different co-surfactants with the screened oil was investigated. $0.2 \mathrm{~g}$ of co-surfactant and $0.3 \mathrm{~g}$ of oil phase were weighed and vortexed for 2 minutes followed by warming at $40-45^{\circ} \mathrm{C}$ for 30 seconds, so we can obtain an isotropic mixture. $50 \mathrm{mg}$ of isotropic mixture was taken and diluted with double distilled water previously filtered through $(0.45 \mu \mathrm{m})$ membrane filter in a volumetric flask. Number of volumetric flask inversions was observed visually to form a clear emulsion. The resulting emulsions allowed standing for $2 \mathrm{hrs}$ after that transmittance were observed at $638 \mathrm{~nm}$. The co-surfactant which forms a clear emulsion with lesser number of inversions and with more transmittance was selected. 
Table 2: Example of surfactants, co-surfactant, and co-solvent used in commercial formulations

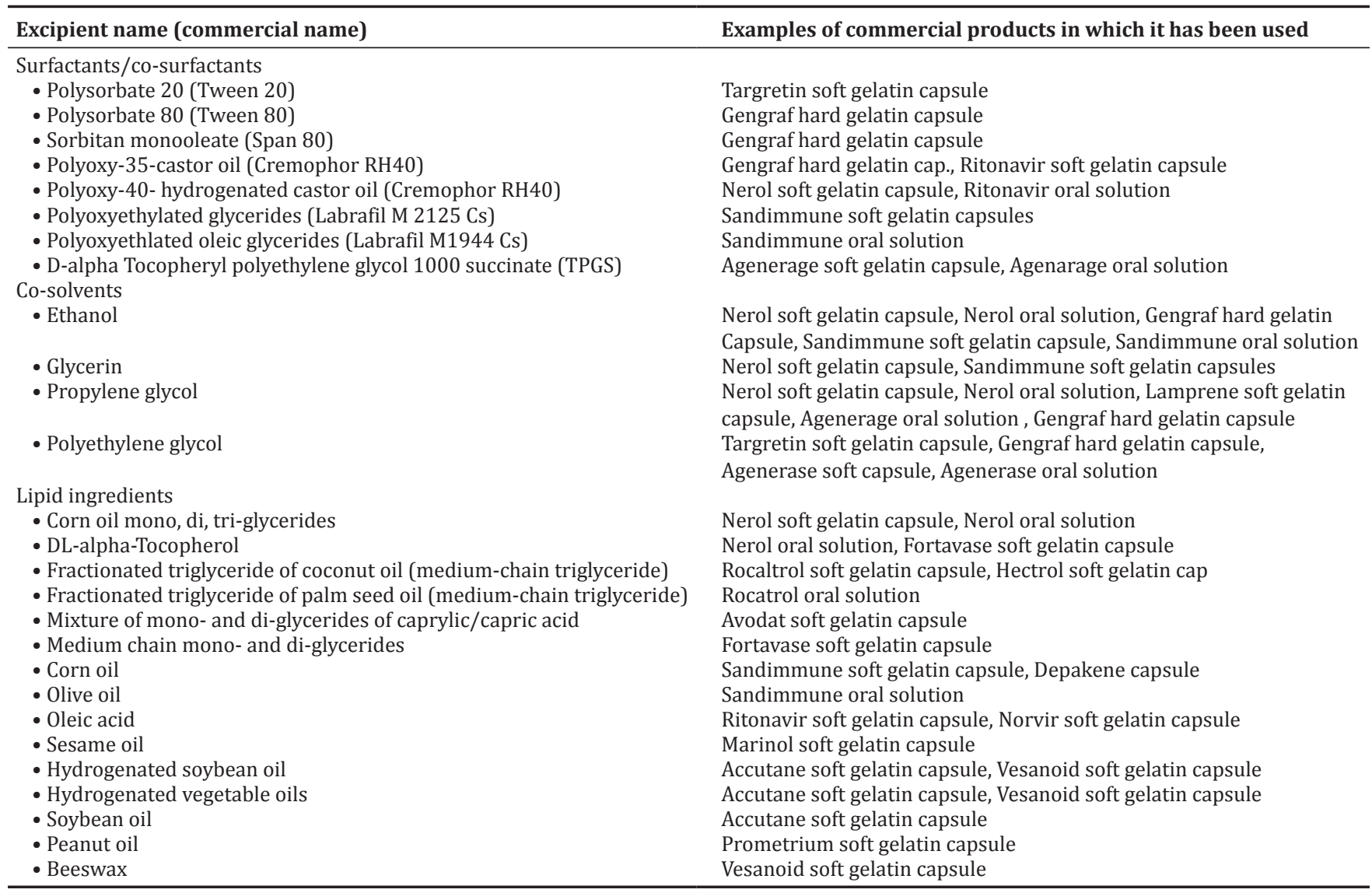

\section{Construction of phase diagram}

Phase diagrams were constructed to obtain the proportion of components that can result in maximum microemulsion existence area These diagrams were constructed with oil, surfactant/co-surfactant and water using water titration method at room temperature. The procedure consisted of preparing solutions of different ratio of surfactant to co-surfactant by weight such as $1: 1,2: 1,3: 1$, etc., these solutions then vortexed for 5 minutes and placed at $50^{\circ} \mathrm{C}$ for $1 \mathrm{hr}$ so that an isotropic mixture was obtained (Fig. 3)

Each of these solutions was then used for preparing a mixture containing oil and Smix (mixture of surfactant and co-surfactant) in the following ratios by weight: $1: 9,2: 8,3: 7,4: 6,5: 5,6: 4,7: 3,8: 2$ 9:1 and after preparation vortexed for 5 minutes followed by placing in oven at $50^{\circ} \mathrm{C}$ for $1 \mathrm{hr}$. All the mixtures were then placed at room temperature for $24 \mathrm{hrs}$. Water from $5 \%$ to $95 \%$ of the mixture was added at 10-15 minutes interval to each of the mixture under stirring on magnetic stirrer. After each addition, the mixtures were observed for their appearance (turbid or clear). Turbidity of the samples would indicate the formation of a coarse emulsion, whereas a clear isotropic solution would indicate the formation of a microemulsion. Percentage of oil, Smix, and water at which clear mixture was formed were selected, and the values were used to prepare ternary phase diagram [17].

\section{Preparation of SMEDDS}

From the ternary phase, diagram ratio of surfactant to co-surfactant was optimized. Then by varying ratio of oil to Smix, different formulations were prepared with and without the drug. Formulations were prepared by preparing optimized ratio of Smix first, for this surfactant and cosurfactant were accurately weighed and then vortexed for 5-10 minutes After that, Smix was placed in an oven at $50^{\circ} \mathrm{C}$ for $1 \mathrm{hr}$. Oil with different ratio was added to Smix then these formulations were vortexed for

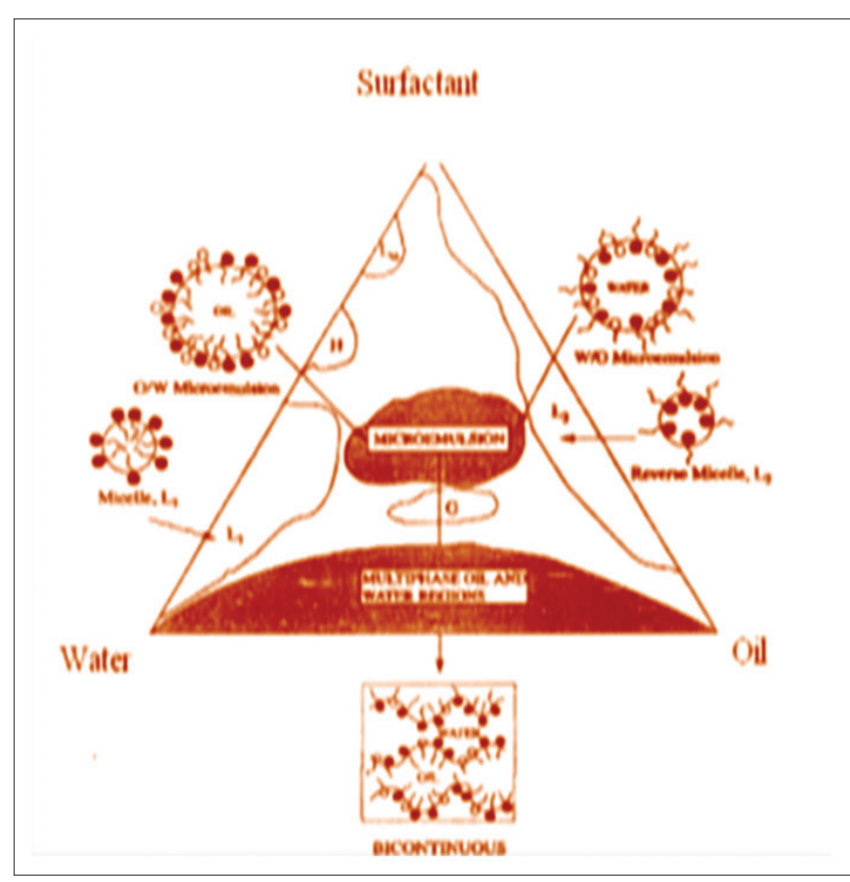

Fig. 3: Construction of phase diagram

5-10 minutes and placed in an oven at $50^{\circ} \mathrm{C}$ for $1 \mathrm{hr}$ so that an isotropic mixture was formed. Drug was loaded to these isotropic formulations at the end and vortexed by vortex shaker until clear solution was obtained [18]. 


\section{EVALUATION OF SMEDDS}

- Determination of droplet size/distribution and zeta-potential: Method use for the determination of droplet size include photon correlation spectroscopy (which analyses fluctuations in light scattering due to Brownian moment of particles) using a zetasizer able to measure size in the range 10-5000 $\mathrm{nm}$. This technique can only be employed at relatively low dilutions for accurate droplet size evaluation. Oil droplets possess some charge on their surface due to the presence of some groups like conventional SMEDDS is negative due to the presence of free fatty acids; however, incorporation of cationic lipids in concentration range 1-3\% will yield cationic SMEDDS Thus, such systems have a positive $n$-potential value of about 35-45 mV. This positive n-potential value is preserved following the incorporation of the drug compounds [19].

- Rheological determination: Brookfield viscometer, rotational viscometer Rheomat 108 can be used for evaluation of rheological properties of microemulsion. This study confirms whether the system is o/w or w/o. It should be performed in triplicate [20].

- Polarity: Polarity of oil droplet is governed by some parameters such as the HLB, chain length, and degree of unsaturation of the fatty acids, molecular weight of the hydrophilic portion, and concentration of the emulsifier. Polarity has an impact on affinity of the drug for oil and/or water, and the type of forces formed. The highest release will be obtained with the formulation that has oil phase with the highest polarity [18]

- Dispersibility test: The efficiency of self-emulsification of oral nano- or microemulsion is assessed using a standard USP XXII dissolution apparatus 2 for dispersibility test. One milliliter of each formulation was added in $500 \mathrm{ml}$ of water at $37 \pm 10^{\circ} \mathrm{C}$. A standard stainless steel dissolution paddle is used with rotating speed of $50 \mathrm{rpm}$ provided gentle agitation. The in vitro performance of the formulations is visually assessed using the following grading system:

- Grade A: Rapidly forming (within 1 minute) nanoemulsion, having a clear or bluish appearance.

- Grade B: Rapidly forming, slightly less clear emulsion, having a bluish-white appearance.

- $\quad$ Grade C: Fine milky emulsion that formed within 2 minutes.

- Grade D: Dull, grayish white emulsion having slightly oily appearance that is slow to emulsify (longer than 2 minutes).

- Grade E: Formulation, exhibiting either poor, or minimal emulsification with large oil globules present on the surface. Grade A and Grade B formulation will remain as Nano-emulsion when dispersed in GIT. While formulations falling in Grade C could be recommend for SEDDS formulations.

- Turbidimetric evaluation: Growth of emulsion can be monitored by doing Nephelo turbidimetric evaluation. A fixed quantity of selfemulsifying system is added to fixed quantity of suitable medium ( $0.1 \mathrm{~N}$ hydrochloric acid) under continuous stirring (50 rpm) on magnetic plate at ambient temperature, and the increase in turbidity is measured using a turbidimeter. However, since the time required for complete emulsification is too short, it is not possible to monitor the rate of change of turbidity (rate of emulsification)

- Refractive index and percent transmittance: Transparency of the formulation is proved by the refractive index and percent transmittance. The refractive index is measured by Refractometer by placing a drop of solution on slide and then by comparing with water (1.333). The percent transmittance of the system is measured at particular wavelength using UV-spectrophotometer keeping distilled water as blank. If refractive index of system is similar to the refractive index of water (1.333) and formulation have percent transmittance $>99 \%$, then formulation has transparent nature [21].

- Electro conductivity test: This test is performed forb measurement of the electroconductive nature of system. The electroconductivity of resultant system is measured by electro-conductometer. In conventional SMEDDSs, the charge on an oil droplet is negative due to the presence of free fatty acids.
- Drug content: Drug from pre-weighed SMEDDS is extracted by dissolving in a suitable solvent. Drug \content in the solvent extract was analyzed by suitable analytical method against the standard solvent solution of drug [22].

- In vitro dissolution testing: The quantitative in vitro release test is performed in US Pharmacopoeia XXIV dissolution apparatus 2, using $900 \mathrm{ml}$ of buffer with $\mathrm{pH}$ (given in pharmacopoeia for the particular drug) as dissolution media, the paddles are set to rotate at $100 \mathrm{rpm}$ and temperature is set at $37^{\circ} \mathrm{C}$. The SMEDDS formulations are put in hard gelatin capsules (size 00), during the drug release studies $5 \mathrm{ml}$ sample of dissolution media is to be taken out for analyzing the sample using HPLC. The removed volume is to be replaced each time with $5 \mathrm{ml}$ of fresh medium. Dissolution studies are also performed in other media (buffer with different $\mathrm{pH}$ ) to study the effect of $\mathrm{pH}$ on drug release [23]

\section{APPLICATIONS OF SMEDDS}

- Enhancement in solubility and bioavailability: SMEDDS formulation enhances the bioavailability by increasing the solubility of drug and also decreases the gastric irritation.

- Super saturable SMEDDS: Super saturable-SMEDDS have been developed to overcome the toxic effect of surfactant or GI side effects produced by surfactant when used in very high concentration as typically used in SMEDDS.

- Protection from biodegradation: Drugs for which both solubility and degradation is low in the GIT contribute to a low oral bioavailability, SMEDDS is useful for such drugs due to the ability to reduce degradation as well as improve absorption [24].

\section{CONCLUSION}

As per the novel drug delivery system, SMEDDS are a promising approach for the formulation of drug compounds with poor aqueous solubility. The oral delivery of hydrophobic drugs which belongs to BCS Class II can be made possible by SMEDDSs, which have been shown to substantially improve oral bioavailability and thus the dose of the drug can be reduced. With future development of this technology, SMEDDSs will continue to enable novel applications in drug delivery and solve problems associated with the delivery of poorly soluble drugs.

\section{ACKNOWLEDGMENTS}

We would like to thank the Institute of Pharmacy, Bundelkhand University, Jhansi for supporting my work. I felt special thankful to Mr. Rishikesh Gupta for his time to time guidance for me.

\section{REFERENCES}

1. Bhatt V, Rathore RP, Tanwar YS. Self miro emulsifying drug delivery system, A review. ARPB 2014;4(2):664-9.

2. Kyatanwar AU, Jadva KR. Self micro-emulsifying drug delivery system. J Pharm Res 2010;3(1):75-83.

3. Mandawgade SD, Sharma S, Pathak S, Patravale VB. Development of SMEDDS using natural lipophile: Application to beta-artemether delivery. Int J Pharm 2008;362(1-2):179-83.

4. Cho SH, Kang BK, Lee JS. Self-microemulsifying drug delivery system for oral bioavailability enhancement, pharmaceutical research. Int J Pharm 2004;274:65-73.

5. Khedekar K, Mittal S. Self emulsifying drug delivery system: A review. IJPSR 2013;4(12):4494-507.

6. Gugulothu D, Pathak S, Suryavanshi S, Sharma S, Patravale V. Selfmicroemulsifiyng suppository formulation of $\beta$-artemether. AAPS Pharm Sci Tech 2010;11(3):1179-84.

7. McConville C, Friend D. Development and characterisation of a selfmicroemulsifying drug delivery systems (SMEDDSs) for the vaginal administration of the antiretroviral UC-781. Eur J Pharm Biopharm 2013;83(3):322-9.

8. Woo JS, Kim TS. Formulation and evaluation of silymarin using SMEDDS. Arch Pharm Res 2007;30(1):82-9.

9. Pimple SS, Yeole SE, Chaudhari PD. Self-micro drug delivery system for poorly water soluble drug. Int J Pharm Sci Res 2013;23(1):155-62.

10. Laddha P, Suthar V, Butani S. Development and optimization of self miro 
emulsifying drug delivery system. Braz J Pharm Sci 2014;50(1):91-9.

11. Li L, Yi T, Lam CW. Effects of spray-drying and choice of solid carriers on concentrations of Labrasol ${ }^{\circledR}$ and Transcutol ${ }^{\circledR}$ in solid self-microemulsifying drug delivery systems (SMEDDS). Molecules 2013; 18(1):545-60

12. Zhu JX, Tang D, Feng L, Zheng ZG, Wang RS, Wu AG, et al Development of self-microemulsifying drug delivery system for oral bioavailability enhancement of berberine hydrochloride. Drug Dev Ind Pharm 2013;39(3):499-506.

13. Sharma B, Sharma A, Arora S. Formulation, and evaluation of calcium loaded microemulsion. J Pharm Drug Res 2012;1:1-7.

14. Nisha GS, Geeta R, Vaishali P. Formulation and evaluation of SMEDDS, Int J Res Pharm Sci 2011;2(2):162-9.

15. Khan BA, Bakhsh S, Khan H. Basics of self-micro emulsifying drug delivery system. J Pharm Altern Med 2012;1:13-20.

16. Nekkannti V, Kalepu S. Novel lipid based drug delivery system. IRJP 2012;3(9):166-73

17. Bhagwat DA, D’Souza JI. Formulation, and evaluation of solid self miro emulsifying drug delivery system. Int Curr Pharm J 2012;1(12):414-9.

18. Patel RN, Rajput AP. In-vivo chariterization of SMEDDS. Int J Pharm Pharm Sci 2013;5(3):793-800.

19. Manoharui PJ, Kunchithapatham J. Development of SMEDDS. Der Pharm 2013;4(6):48-58

20. Rai S, Yasir M. Cinnarizine loaded lipid base system. ISOR J Pharm $2012 ; 2: 47-56$

21. Harshal DM, Rajendra DW, Tanvvir S. Design and development of self-micro emulsifying drug delivery system. Int J Curr Pharm Res 2011;5(4):163-5

22. Sha X, Wu J, Chen Y, Fang X. Self-microemulsifying drug-delivery system for improved oral bioavailability of probucol: Preparation and evaluation. Int J Nanomedicine 2012;7:705-12.

23. Cai S, Yang L, Suo H. Self-micro emulsifying drug delivery system for improved oral bioavailability. Int J Nanomedicine 2014;9:913-20.

24. Wei JD, Ho HO, Chen CH, Ke WT, Chen ET, Sheu MT. Characterisation of fenofibrate dissolution delivered by a self-microemulsifying drugdelivery system. J Pharm Pharmacol 2010;62(12):1685-96. 